\title{
THE RIVET PARAMETER INFLUENCE IN FATIGUE STRENGTH
}

\author{
Ion Fuiorea, Daniela Bartis, Roxana Nedelcu \\ Military Technical Academy, Bucuresti, Romania \\ Adrian Mocanu \\ Polytechnic University, Bucuresti, Romania
}

\begin{abstract}
The paper deals with the experimental analysis of the influence of the rivet parameters upon the fatigue strength of aircraft structures.

Different riveted samples were tested on fatigue machine taking into account the diameter of the rivet and the forming pressure influence.

By superposing the resulting Wöhler curves on the same graphic, some interesting conclusions were pointed.
\end{abstract}

\section{INTRODUCTION}

The Romanian Research Authority is financing a project developing design, prototype manufacture \& test and certificate a CS23 aircraft. Inside this project STRAERO was involved with tasks consisting in design and structural test. During the preliminary technical \& economical study, our institute participates at a research task consisting in the study of the influence of the constructive and technological parameters upon the fatigue strength of the riveted connections of the structure. The main considered parameters were: the type of rivet head (round head and countersunk), the diameter of the rivet versus the connected blade thickness and the riveting force.

The present work deals with the interpretation of the results that were obtained during the fatigue physical tests that were performed on a great number of riveted specimens with different constructive and technological parameters. The results are considered the database for preliminary structure life estimation.

\section{TYPES OF SPECIMENS}

The tested specimens were designed to cover the groups of studied parameters of the riveted assembly:

a) shape of the specimen (presented in fig. 1)

b) Diameter of the rivet: $3.8 \ldots 5.25 \mathrm{~mm}$

c) Thickness of the blades: $1 \ldots 1.6 \mathrm{~mm}$

d) Type of rivet head: round, countersunk (fig. 1)

e) Number of riveted rows: 1 .. 2 

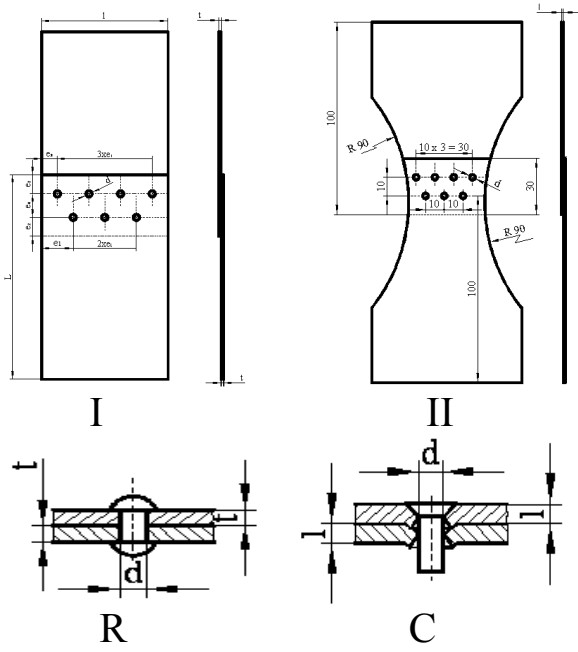

Fig. 1. Types of the specimen

In the Table 1 a brief presentation of the cases of the specimens were presented.

Table 1. Types of specimens

\begin{tabular}{|c|c|c|c|c|c|c|c|c|c|c|c|c|}
\hline 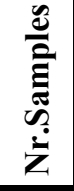 & 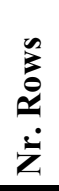 & $\begin{array}{l}\frac{n}{0} \\
\dot{a} \\
\dot{z} \\
\dot{z}\end{array}$ & $\frac{\bar{\Xi}}{\bar{\Xi}}$ & $\underline{\underline{\Xi}}$ & $\begin{array}{l}\bar{\Xi} \\
\bar{\Xi}\end{array}$ & $\frac{\bar{\Xi}}{\bar{\Xi}}$ & $\frac{\bar{\Xi}}{\tilde{\Xi}}$ & $\frac{\bar{\Xi}}{\mathscr{\Xi}}$ & 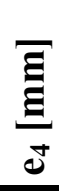 & $\frac{\bar{\Xi}}{\mathrm{E}}$ & 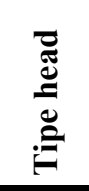 & 离 \\
\hline 48 & 2 & 8 & 5.1 & 80 & 130 & 20 & 12 & 12 & 20 & 1,6 & $\mathrm{R}, \mathrm{C}$ & I, II \\
\hline 48 & 2 & 8 & 5.25 & 80 & 130 & 20 & 10 & 10 & 20 & 1,6 & $\mathrm{R}$ & I, II \\
\hline 48 & 1 & 4 & 4.8 & 80 & 130 & 20 & 14 & 12 & - & 1,6 & $\mathrm{R}, \mathrm{C}$ & I, II \\
\hline 24 & 2 & 7 & 4 & 80 & 130 & 20 & 8 & 10 & 15 & 1 & $\mathrm{R}$ & II \\
\hline 24 & 2 & 7 & 3.8 & 80 & 100 & 15 & 7 & 7 & 12 & 1 & $\mathrm{R}$ & II \\
\hline
\end{tabular}

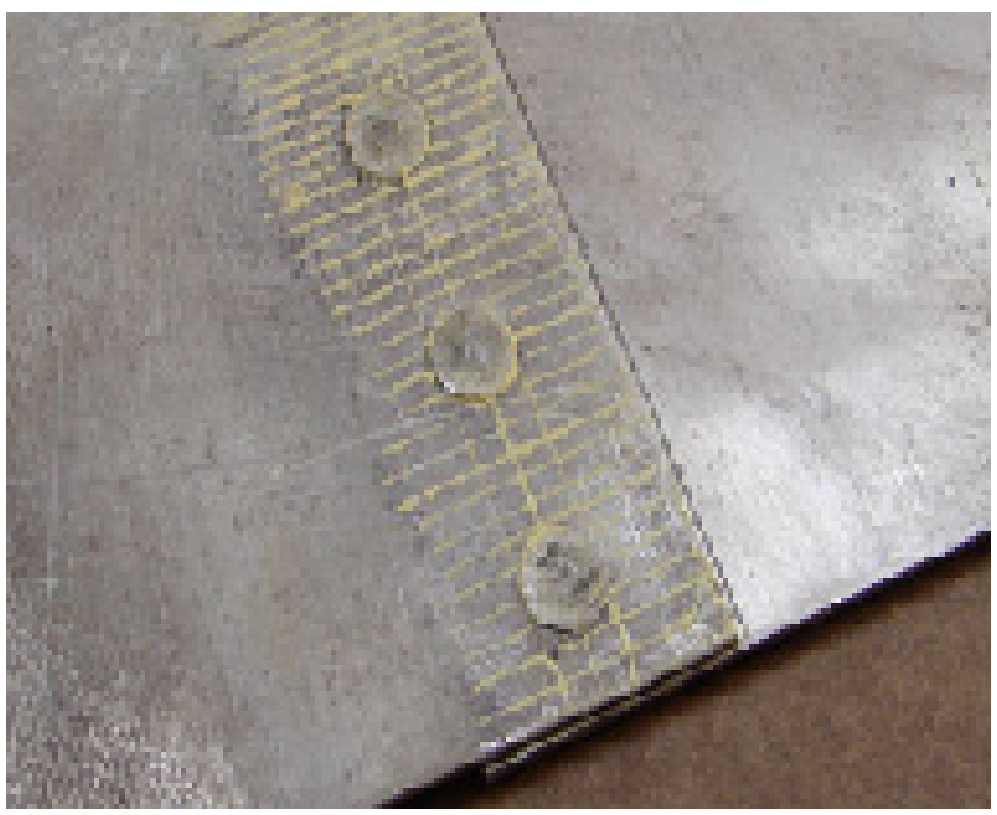

Fig. 2. Grid on the specimen 
N.B. In order to have a good estimation of the crack development, a corresponding grid was drawn on the surfaces of the samples as shown in the fig. 2.

\section{CONDITIONS OF TESTING}

According to the regulation prescriptions the fatigue tests were performed in the ambient conditions:

- Temperature $.18 \div 20^{\circ} \mathrm{C}$

- Humidity $.65 \pm 5 \%$

- Atmospheric pressure $860 \div 1060$ mbar.

The loading cycle is gently and progressively applied. The number of cycles counted before reaching the chosen cycle is not considered for the durability estimation. In order to avoid the inertial behaviour the frequency was recommended as $2 \div 50$ cycles/second. The test was not interrupted until the final crack.

The chosen cycle is considered to be unsymmetrical with $\mathrm{R}=0.1$ and the loading scheme is indicated to be applied as it follows:

- The Sample 1 to be loaded at $\sigma_{\max }=\sigma_{1}$, where $\sigma_{1}=0.4 \sigma_{\mathrm{r}}$.

- The Sample 2 to be loaded at $\sigma_{\max }=\sigma_{2}$, where $\sigma_{2}=\sigma_{1} .-(10 \div 20) \mathrm{MPa}$ etc.

For example for the first type of specimens, for the first step of loading, there were considered:

$\mathrm{R}=0.1 ; \sigma_{\mathrm{r}}=460 \mathrm{MPa}$; frequency $=10 \mathrm{~Hz}$ and corresponding

$$
\begin{aligned}
& \sigma_{1}=\sigma_{\max }=0.4 \cdot \frac{\sigma_{r}}{\alpha_{k}}=61.3 \mathrm{MPa}, \\
& \sigma_{\min }=R \cdot \sigma_{\max }=6.13 \mathrm{MPa}, \\
& \sigma_{m}=\frac{\sigma_{\min }+\sigma_{\max }}{2}=33.75 \mathrm{MPa}, \\
& \sigma_{v}=\frac{\sigma_{\max }-\sigma_{\min }}{2}=27.58 \mathrm{MPa} .
\end{aligned}
$$

The fatigue tests were performed on a hydraulic SCHENK testing machine with maximum cylinder force of $60 \mathrm{kN}$. Special measures were taken to assure the axially loading to avoid the bending effect of the specimen as shown in figure 3 . The crack evolution was monitorised by using a very low speed video camera.

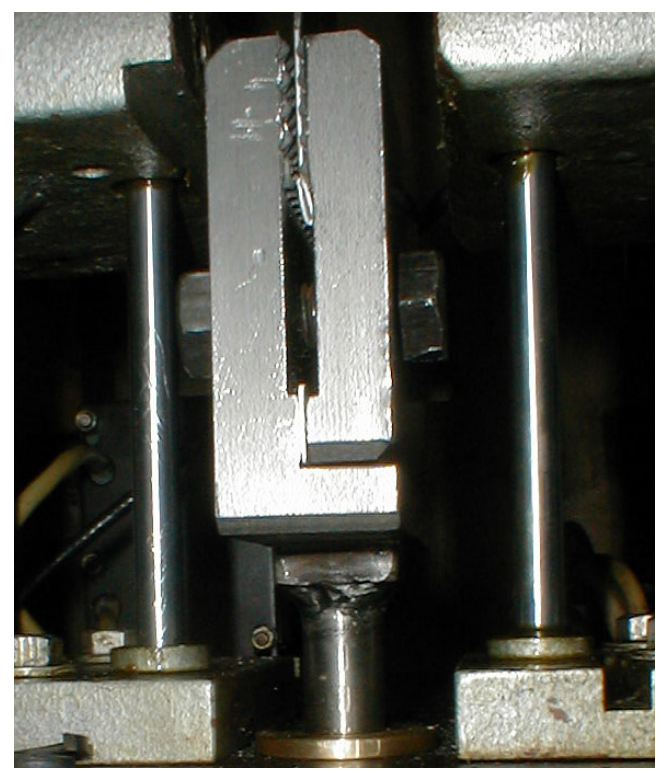

Fig. 3. Specimen clamping 


\section{TESTING RESULTS}

Each test was considered to be performed when the final rupture of the specimen took part. A statistic calculus was performed for each group of tests (3 samples) for similar type of sample, similar loading scheme and suggestive fatigue diagrams were realised as it will be presented in the following figures. Six loading schemes were considered for each type of test.

Finally the entire data base results were analysed together in order to draw general conclusions presenting the influences of the parameters of the riveting technology upon the fatigue strength of the specimens.

As an example the analysis for the results connected to the first type of specimen are presented next.

In the table 2 there are presented the average results for the first type of specimen.

Table 2. Test results for the type 1 of specimen (according to the table 1)

\begin{tabular}{|c|c|c|c|c|c|c|c|c|c|}
\hline Pos. & $\begin{array}{c}\mathbf{N r} . \\
\text { of spec }\end{array}$ & $\begin{array}{c}\boldsymbol{\sigma}_{\max } \\
{[\mathbf{M P a}]}\end{array}$ & $\begin{array}{c}\boldsymbol{\sigma}_{\min } \\
{[\mathbf{M P a}]}\end{array}$ & $\begin{array}{c}\mathbf{F}_{\mathbf{m a x}} \\
{[\mathbf{N}]}\end{array}$ & $\begin{array}{c}\mathbf{F}_{\min } \\
{[\mathbf{N}]}\end{array}$ & $\begin{array}{c}\Delta \mathbf{F} \\
{[\mathbf{N}]}\end{array}$ & $\begin{array}{c}\mathbf{\sigma}_{\mathbf{v}} \\
{[\mathbf{M P a}]}\end{array}$ & $\begin{array}{c}\mathbf{e} \\
{[\mathbf{m m}]}\end{array}$ & $\begin{array}{c}\mathbf{N} \cdot \mathbf{1 0}^{\mathbf{3}} \\
\mathbf{c y c l e s}\end{array}$ \\
\hline 1 & 3 & 61 & 6.1 & 7808 & 780.8 & 7027.2 & 27.45 & 7.87 & 263 \\
\hline 2 & 3 & 55 & 5.5 & 7040 & 704.0 & 6336 & 24.75 & 7.1 & 357 \\
\hline 3 & 3 & 50 & 4.8 & 6144 & 614.4 & 5529.6 & 21.6 & 6.19 & 557 \\
\hline 4 & 3 & 45 & 4.5 & 5760 & 576.0 & 5184 & 20.25 & 5.81 & 738 \\
\hline 5 & 3 & 41 & 4.1 & 5248 & 524.8 & 4723.2 & 18.45 & 5.29 & $* 1210$ \\
\hline 6 & 3 & 41 & 4.1 & 5248 & 524.8 & 4723.2 & 18.45 & 5.29 & $* 1898$ \\
\hline
\end{tabular}

*No cracks - the test stopped

It can be noticed that for the loadings corresponding the positions 5 and 6 no crack appears and, as a consequence the tests were stopped according to the regulation prescriptions.

In the figure 4 the Wöhler curves are presented both in Cartesian and logarithmic coordinates.

Type $1_{\text {pu } 1}$

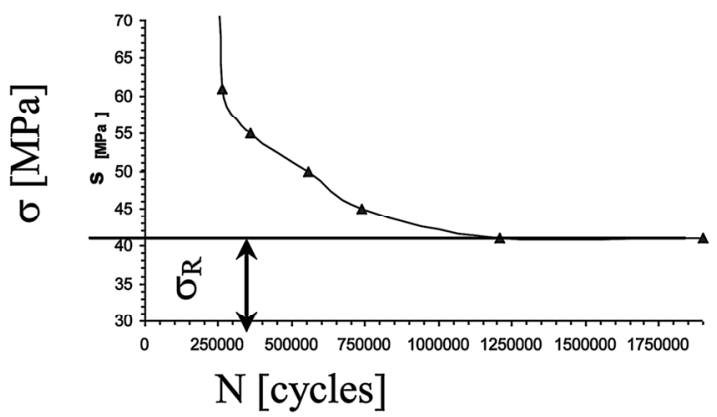

Type 11

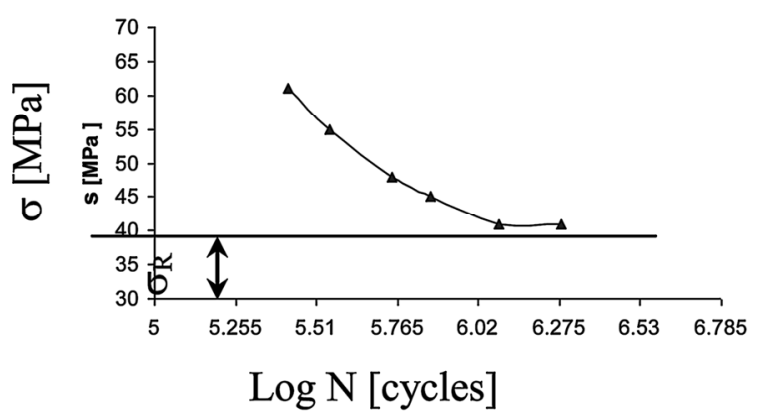

Fig. 4. Wöhler curve for the first type of specimen 


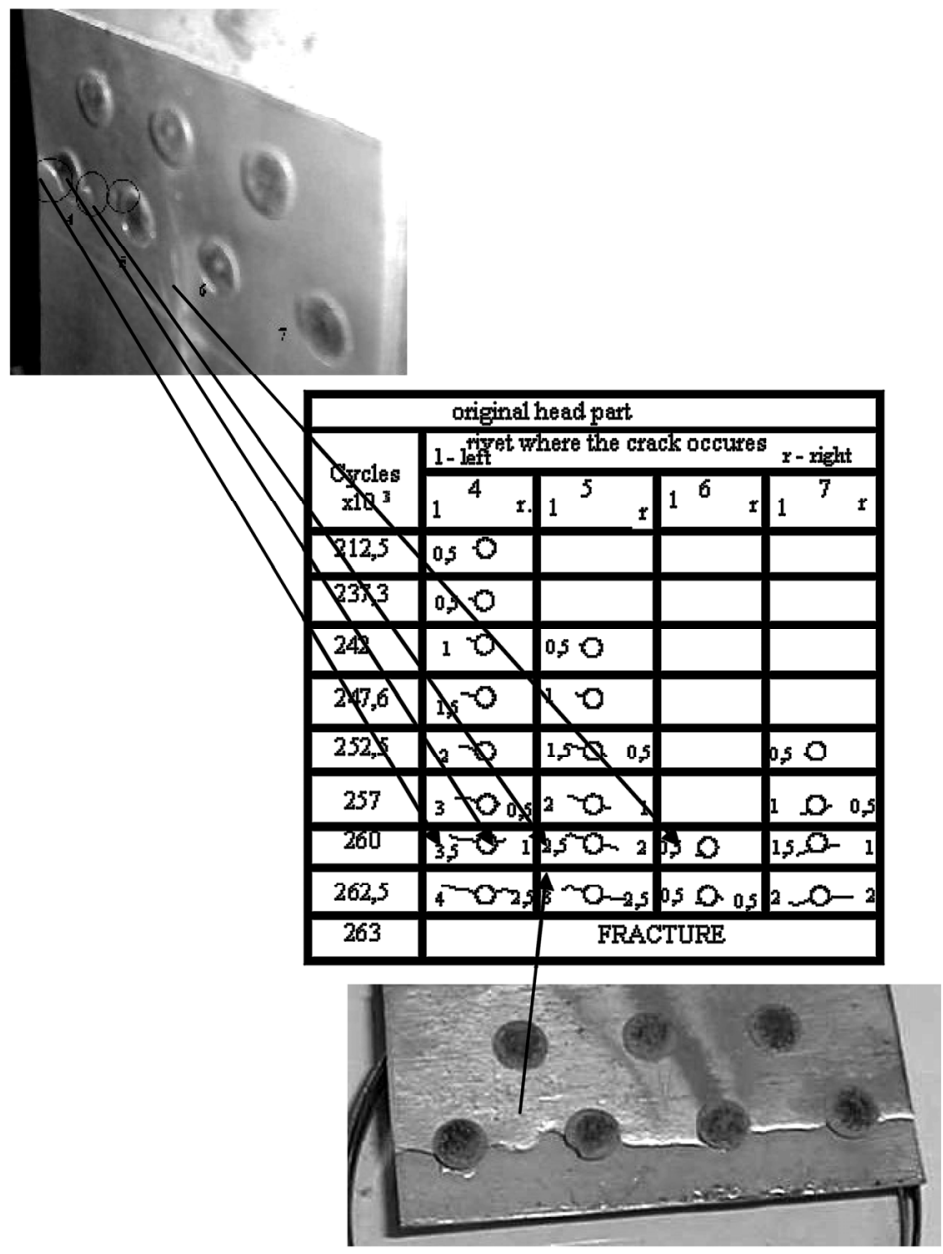

Fig. 5. Scheme of crack apparition and propagation

In the figure 5 it is presented the scheme of the crack apparition and development for different time steps and a intermediate picture sustaining the description.

It can be observed that the cracks appear on the row with 4 rivets and starts near the rivet number 4 on the left side. Afterwards the crack develops near the rivet 5 and afterwards to 6 and 7 ones. It is interesting to observe that despite the fact that the crack is initially oriented towards up and/or down; during the propagation it has the direction along the rivet row as presented in Fig. 6 .

Similar studies were done for all types of specimens that were manufactured

\section{CONCLUSIONS}

- A number of 192 specimens were tested representing 5 constructive types. Separate tests were performed to determine the statically ultimate strength, $\sigma_{R}$.

- The results obtained after all tests demonstrate that for maximum values $\sigma_{\max }<\sigma_{R}$ of the harmonic cycles no cracks appear for a number less than 75 Kcycles. This result was valuable for all types of specimens, all types of rivet heads and all geometrical parameters of the riveted scheme.

- The cracks started always near the extreme rivet and started from the end part of the conical hole of the countersunk rivet near the cylindrical bare as presented in figure 7 . That is a major disadvantage of this type of rivet because the beginning of the crack is hidden by the head of the rivet and they cannot be detected during the inspections. And in all cases, the cracks begin near the cylindrical bare of the rivet. That makes invisible the first 1-3 
millimetres of the beginnings cracks. Alternate non-destructive methods of inspections must be considered in the maintenance process. The mechanism of the fracture is a consequence of the joining of a visible crack with an invisible one: the initiation of a crack at a rivet hole margin; because of fatigue process the crack grows arriving at the exterior surface; another crack in initiating at the next rivet hole, invisible and smaller; the two cracks grow and the invisible one appear suddenly joining with the first, etc.

- The influence of the plastic deformation force of the rivet upon the crack initiation location was considered in a qualitative way considering the diameters of the formed heads of the rivets as presented in table 3 . Big values of the deformation force implies a greater friction force between the riveted plate and a low shearing load upon the cylindrical body of the rivet.

- A superposition of the Wöhler curves for different types of specimens allows interesting conclusions regarding the influence of the riveting parameters influence upon the fatigue strength, as shown in figure 8:

- The number of cycles where the sample brakes down is decreasing with respect to the diameter of the rivet decreasing.

- The ultimate fatigue strength of the specimen for the round head is inferior to the countersunk ones and this in explained by the major pressure of the deformation load in this case (round head).

- The two riveted rows cases were more resistant in the fatigue tests with respect to one riveted row.

- The number of kilocycles until the initiation of the crack represents the major part of the total number of kilocycles until fracture, the crack growth until fracture representing approximately $25 \%$ from the total fatigue life of the jointed plates.

Table 3. The plastic deformation force of the rivet estimation versus the diameters of the formed heads

\begin{tabular}{|c|c|c|c|c|}
\hline Nr. of rivet & 4 & 5 & 6 & 7 \\
\hline Diameter of the formed head [mm] & 4,19 & 4,17 & 4,05 & 4,10 \\
\hline
\end{tabular}

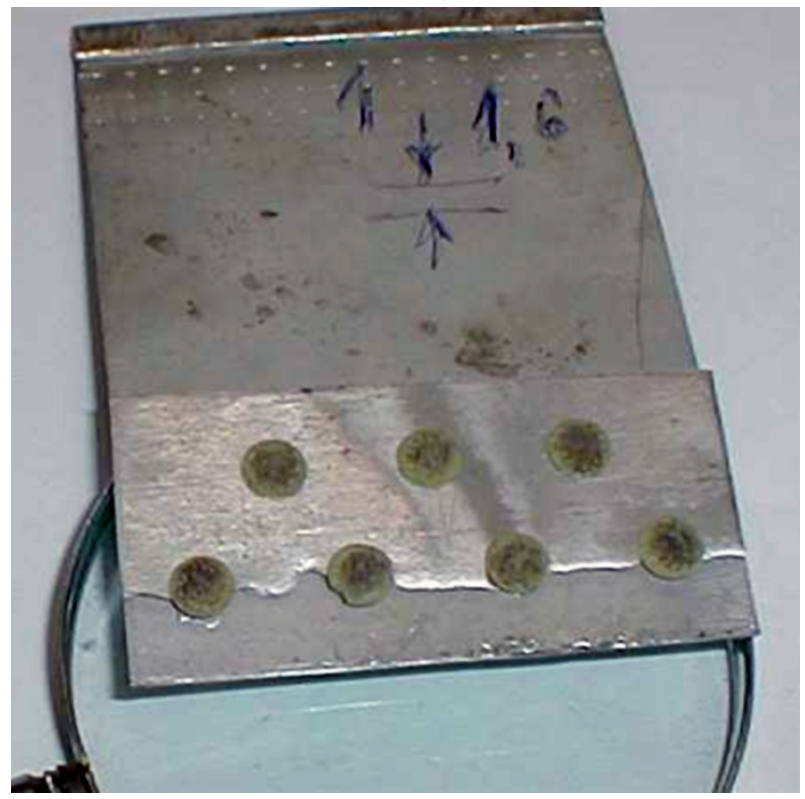

Fig. 6. The final crack orientation 


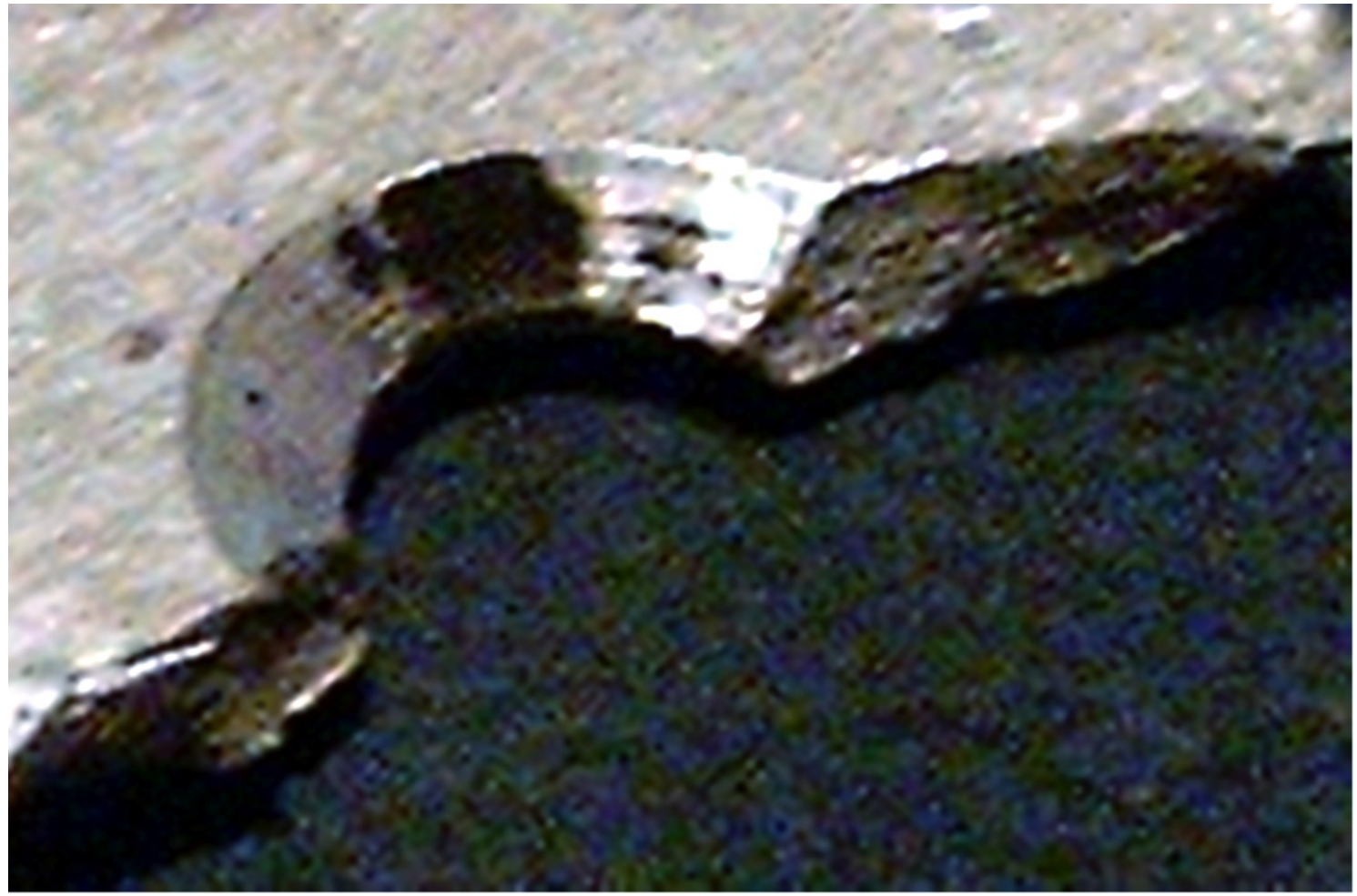

Fig. 7 The crack initiation at the extreme rivet at the conical hole of the rivet

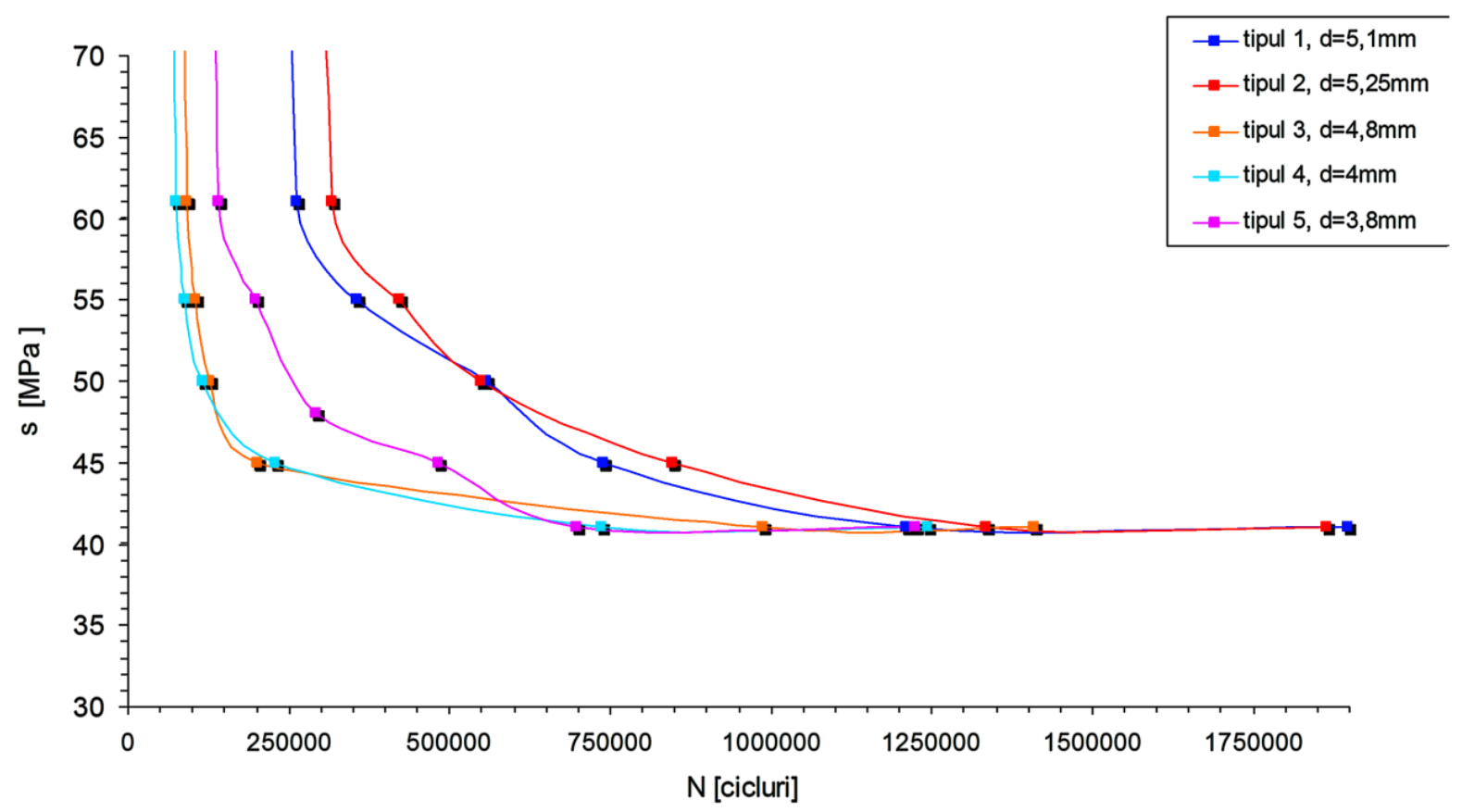

Fig. 8 The superposition of the Wöhler curves for different types of specimens 


\section{BIBLIOGRAPHY}

[1] Aktepe, B., \& Molent, L. (1999). Management of Airframe Fatigue Through Individual Aircraft Loads Monitoring Programs. Defense Science and Technology Organization, Aeronautical and Maritime Research Laboratory, Victoria, Australia.

[2] Apicella, A., Armentani, E., \& Citarella, R. (1998). Crack Propagation in MultiSite Damage Condition for a riveted Joint. Fisciano: Department of Mechanical Engineering, University of Salerno.

[3] Apicella, A., Armentani, E., \& Citarella, R. (1997). Bidimensional Stress Analysis and SIF's Assessement of a Cracked Aeronautic Doubler-Skin Assembly by BEM and FEM. Fisciano: Department of Mechanical Engineering, University of Salerno.

[4] Bakuckas, J., Jr. (January 06, 2005). Structural Integrity of transport Airplanes. Airworthiness Assurance Branch, AAR-480, Atlantic City International Airport, from http://airportaircraftsafetyrd.tc.faa.gov/Programs/agingaircraft/Structural/index.htm

[5] Bruhn, E. (1965). Analisys and design of flight vehicle structures. Cincinnati, Ohio: Tri-State Offset Company.

[6] Cali, C., Citarella, R., \& Soprano, A. (1998). FEM-BEM coupled methodolgy for cracked stiffened panels. Boundary Element Comunications Journal, 8(4).

[7] Findlay, S., \& Harrison, N. D. (2002). Why aircraft fail. Materials Today, November 2002, ISSN: 1369 7021. Hampshire, United Kingdom: Elsevier Science Ltd. 2002, QinetiQ Ltd.

[8] Keller, E. (2001, May). Real-Time Sensing of Fatigue Crack Damage for Information-Based Decision and Control. A thesis in Mechanical Engineering, The Pennsylvania State University, The Graduate School College of Engineering.

[9] Khor, K., \& Ubhi, H. (2001). Fatigue Crack Closure Studies In Advanced Airframe Aluminium Alloys. Materials Research Group, School of Engineering, Highfield, United Kingdom: University of Southhampton.

[10] Ko, L. W. (1987, May). Prediction of Service Life of Aircraft Structural Components Using the Half-Cycle Method. Ames Research Center, Dryden Flight Research Facility, Edwards, California: NASA Technical Memorandum 86812.

[11] Rusmee, P. (2005, September). Fatigue Crack Growth. Retrieved July 27, 2010, from www.mech.utah.edu/ rusmeeha/lab Notes/fatigue.html

[12] Silva, A. (1997). Multiple Site Damage in Riveted Lap-Joints Specimens. Warrington, United Kingdom: EMAS Publishing.

[13] Vlieger, H., \& Ottens, H. (1998, October). Uniaxial and biaxial tests on riveted fuselage lap joints specimens. Office of Aviation Research Washington, U. S. Departament of Transportation, Federal Aviation Administration. (DOT/FAA/AR-98/33) 